\title{
EDITORIAL
}

\section{Ave atque vale}

Readers of the British Journal of Venereal Diseases will notice with great regret that Colonel L. W. Harrison has retired from his position as Editor. - The project and formation of the Journal eighteen years ago were, as many of our readers are well aware, to a great extent the result of Colonel Harrison's vision, initiative and enthusiasm. From the first issue of the Journal in 1925 until last year he has been its main driving force, for many years as Co-Editor and for the last four years as Editor. During this seventeen year period the Journal and its readers have been greatly indebted to Colonel Harrison for his constant devotion and indefatigable energy. It is a tribute to his wise guidance and sound judgment that the British Journal of Venereal Diseases has maintained a high standard throughout the long period of his Editorship. The burden has been a heavy one for it fell to Colonel Harrison not only to nurse the Journal through the troubled years of its infancy but also to shoulder the main burden created by the many restrictions and difficulties consequent upon the present war. He has found time, too; to contribute numerous and authoritative papers covering the whole field of his subject.

Less evident but no less valuable has been his very generous help, ready encouragement and constructive criticism which will be remembered with gratitude by many contributors to our pages. Among them there will be few who cannot recall without admiration the final lustre imparted to their manuscripts by his skilful yet tolerant editorial pen.

Contributors and readers alike unite wholeheartedly with the Editorial Board in their expression of gratitude to Colonel Harrison for his long and valuable services to the Journal. It is hoped that the new Editorial Board may have for many years to come the benefit of his mature judgment and rich experience.

\section{Publishing changes}

The burden of war-time restrictions shouldered by publishers of medical journals has been exceptionally heavy and has led to unavoidable changes. Thus it falls to us to announce a change of publishers and to record our appreciation of the unfailing service and courtesy of Messrs. C. Constable and Co., who have been responsible for the production of the first eighteen volumes of the Journal.

The Editorial Board has no doubt in its mind that both readers and contributors will continue to give their loyal support to the Journal. We are sure that they will join with us in wishing every success in their new venture to Messrs. Butterworth and Co., who are undertaking the publication in most difficult circumstances.

Another change of importance to all concerned with venereal diseases is the resumption of quarterly publication of the British Journal of Venereal Diseases.

Unfortunately, there has been an unavoidable delay in the publication of this number, which is properly due for issue on the 1st March. Subscribers will no doubt appreciate the difficulties. The next number, dated June, will be published about the last week in June. During the course of each year the publication dates will then be 1st March, 1st June, 1st September, and 1st December.

\section{Regulation 33B}

The recent addition in November 1942 to the Emergency Powers (Defence) General Regulations, now becoming familiar under the term. Regulation 33B, is dealt with at some length in this issue. The valuable commentary by $\mathrm{Mr}$. N. P. Shannon will doubtless prove useful now and in the future in the files of our readers.

The new Defence Regulation enables compulsion to be applied in limited cases. The voluntary basis of the existing measures to deal with venereal infection remains unaltered but there is now added a provision for compulsion to bring under treatment the small but dangerous group of infected persons of either sex who are 
known to be spreading infection and who are not under medical care. The new measure whilst falling far short of the general notification of venereal cases is more comprehensive than it would appear at first sight, for it necessitates the notification of the name and address of every patient who provides the identification details of the person from whom infection was acquired, but who, nevertheless; may not be traceable.

It will be recalled that at a discussion in April last year, at a meeting of the Medical Society for the Study of Venereal Diseases, and which was subsequently reported in full in these columns, the pressing need for further legislative and administrative powers to control the spread of venereal diseases was urged by a large majority of the members. A resolution on the need for such control was passed at the meeting and subsequently sent to the Ministry of Health and other authorities. Although the desire for some legislative measure was stressed it was also clear that many members considered that the education of the general public on the nature and danger of venereal disease infection needed immediate and full attention.

Medical opinion, in the Forces or in civilian practice, as well as lay opinion, has expressed uneasiness since the time of that discussion as to the adequacy of the pre-war methods to cope with the problem in the third year of war. Such doubts have lent support to the Minister of Health in his decision to supplement the Emergency Powers with Regulation 33B. The regulation, which deals with only a small but important aspect of the problem, will need a considerable time to prove its worth, but its suitability to deal with the most dangerous link in the chain of infection is undoubted.

It is clear from the Notes for the Guidance of Special Practitioners-in practically all cases such practitioners are Service or civilian venereal diseases officers - that other medical practitioners who may treat venereal patients have no obligation as regards notification of their contacts. On the other hand they are at liberty to continue the treatment of any of their venereal patients, although the patients may be contacts notifiable under the Regulation. The onus of deciding whether or not the treatment of the contact is and continues to be adequate and regular is laid on the special practitioner who may see the contact on one occasion only under the order issued by the area Medical Officer of Health. The position of the special practitioner concerned is likely to be an unenviable one and on some occasions such an arrangement may prove to be inadequate unless the special practitioner is entitled to obtain full details of attendances of the patient at regular intervals. There appears to be no obligation on the part of any other practitioner to inform the special practitioner of the adequacy or regularity of the treatment of their patient. In the event of a special practitioner accumulating a long list of contact cases found to be already under treatment by other practitioners the extra-mural control of such shadow patients will become an onerous and uncomfortable burden unless there is very full and ready cooperation on the part of both practitioners.

An attempt to deal with the problem on a much wider scale by actively promoting enlightenment of the general public was inaugurated by the Ministry of Health last autumn. The radio broadcast in October by Sir Wilson Jameson, the Chief Medical Officer to the Ministry of Health, on Tuberculosis and Venereal Diseases, was a masterly and well-timed first introduction of the subject of venereal diseases to the radio public in Great Britain. The innovation in radio approach is a noteworthy milestone in a eampaign of education and it has resulted in congratulations to Sir Wilson Jameson in which we participate. For those readers who were unable to listen to his historical radio talk we reproduce the text in this issue. Another part of the programme of enlightenment has been innovated by the publication of informative articles in the daily press. At last the barriers of silence on venereal diseases have been broken through. The forward step has the approval of venereal diseases officers who are well aware that the younger generation is far more receptive and responsive to education on the subject than is generally believed. 